\title{
Research Towards an Expanded Understanding of Inquiry Science Beyond One Idealized Standard
}

\author{
NANCY BUTLER SONGER, HEE-SUN LEE, SCOTT MCDONALD \\ School of Education, The University of Michigan, Ann Arbor, MI 48109-1259, USA
}

Received 5 September 2001; revised 12 April 2001; accepted 22 May 2002

\begin{abstract}
The work presented builds on a multiyear effort to study the implementation and adaptation of Kids as Global Scientists (KGS), an inquiry-based, technology-rich middle school learning environment enacted simultaneously in hundreds of classrooms across the nation. Two groups of teachers participated in this study. One group consists of "maverick" teachers: those distributed across the nation that find us and customize our program to their needs without systematic professional development. This group of teachers tends to work in schools with a relatively rich fund of resources and supports. Another group - urban teachers - resulted from a recent partnership between KGS and teachers from a large, high-poverty urban school district. We provide these teachers with targeted professional development to help them overcome constraints common to their schools. This study provides profiles of both maverick and urban teachers, and then examines teacher and student data from five focus classrooms that were successful in implementing KGS. In all cases, successful classrooms were defined as those where students made significant positive gains on open-ended and multiple-choice assessments. The focus classrooms consisted of three classrooms from urban teachers in high-poverty environments and two classrooms from maverick teachers in middle-class suburban environments. The paper discusses the need for research that provides multiple exemplars of classroom science inquiry that are realized through large-scale enactments responsive to diverse learning environments. (C) 2003 Wiley Periodicals, Inc. Sci Ed 87:490-516, 2003; Published online in Wiley InterScience (www.interscience.wiley.com). DOI 10.1002/sce.10085
\end{abstract}

\section{INTRODUCTION}

Although "scientific literacy for all" is a foundation of many current policy documents and national science standards (i.e., National Research Council, 1996; U.S. House of Representatives, 2001), few K-12 science education programs have proven successful in meeting this high standard. The persistent reality of scientific literacy for a few challenges science educators to explore how new curricular approaches, models of enactment, and innovative school practices might promote meaningful science learning for

Any opinions, findings, and conclusion or recommendations expressed in this publication are those of the authors and do not necessarily reflect the views of the National Science Foundation.

Correspondence to: Nancy Butler Songer; e-mail: songer@umich.edu

Contract grant sponsor: National Science Foundation.

Contract grant numbers: REC-9805472 and REC-9896054. 
the range of learners prevalent in today's classrooms. Essential to this work are questions about how scientific literacy is conceptualized and the manner in which it is effectively promoted.

Recent work in science education research and curriculum development has taken up these questions. Many curricula programs have been designed to support students as they formulate questions, design experiments, collect scientific data, analyze these data for patterns and conclusions, and develop rich explanations that justify and extend their evidence. These dimensions of scientific thinking represent a subset of the conceptual understandings commonly called scientific inquiry (National Research Council, 2000). Research demonstrates that inquiry programs that foster students' questioning, explanation-building, and prediction-making lead to strong and lasting conceptual understandings of fundamental scientific concepts (Bransford, Brown, \& Cocking, 2000; White \& Fredricksen, 1998). In addition, inquiry programs often emphasize (1) a view of science as "preparation for life" rather than preparation for advanced science careers (Hurd, 1997, p. 79), (2) scientific knowledge as productive information used to solve real-world problems, and (3) scientific knowledge as dynamic and organic, in other words applying to students own' lives and "expanding in meaning or significance each time it is used" (Hurd, 1997, p. 80).

Since inquiry is at the core of what it means to be scientifically literate, this study focused on the promotion and evaluation of inquiry thinking among a wide range of learners. This research first describes two rather distinct types of classroom populations and learning environments, then discusses and provides demonstrable evidence of inquiry thinking among members of both these groups. Inquiry thinking involved in this study includes explanation building, prediction making, and the integration of conceptual understandings of foundational scientific ideas with the productive application to naturally occurring problems in atmospheric science. This investigation of successful inquiry science across two distinct school contexts suggests the need for an expanded conception of inquiry beyond one idealized standard.

\section{What Evidence of Classroom-Based Inquiry Exists?}

While work to develop, coordinate, and conduct research with inquiry programs exists, we believe that many curriculum developers and researchers, including ourselves, have not provided enough evidence of successful inquiry programs among a wide range of classrooms and learners. Despite pockets of evidence of strong learning gains in a range of classroom settings (e.g., White \& Fredricksen, 1998; Kahle, Meece, \& Scantlebury, 2000), the field remains somewhat uninformed about the challenges of implementing inquiry science programs across a range of classroom settings and learners.

There are many good reasons why this research is underdeveloped. In many schools, the pressure to perform well on high-stakes standardized tests crowds out teachers' ability to try more risky, in-depth inquiry science programs. In many classrooms, individual teachers do not have the resources or infrastructure to take on these innovative but challenging programs. Often the complexity involved in supporting in-depth inquiry in classrooms disallows researchers from working with many different classrooms at one time or working at all within schools where teachers are working with enormous constraints, such as is often the case in urban environments. As a result, much of the research that has explored classroom-based inquiry science draws from privileged classroom settings with teachers we call maverick teachers: the self-starter, risk-taking teachers that tend to have a great deal of initiative, autonomy, and support for the range of innovative programs and ideas they implement. Classrooms of maverick teachers also tend to contain many 
resources and supports per student, often including assistance from administrators, educational researchers, technology experts, and/or parent/guardians (Songer, Lee, \& Kam, 2002).

Our work suggests that while many researchers might wish to study innovative inquiry programs in classrooms with more typical resources and teachers, few programs systematically explore learning with these populations, and therefore few programs are able to speak to the range of issues about how to support inquiry science with populations and classrooms that are more typical and widespread. This study was designed to expand our understanding of classroom-based inquiry science through the investigation of one innovative inquiry program adapted to two different learning environment contexts. By context, we refer to both the physical learning environment, including materials, supports, and constraints placed on the teacher, as well as the populations involved, including the teachers, students, their backgrounds, class sizes, and other salient population dimensions. Through the presentation of data from inquiry classrooms of two different learning environment contexts, this research supports an expanded dialogue on a more comprehensive understanding of classroom-based inquiry science than that available through the study of the maverick classrooms often studied by research projects such as ours.

Thus, this research is designed to investigate and compare diverse examples of classroombased scientific inquiry for three reasons. First, many of the current models of what scientific inquiry entails, including studies that examine inquiry programs across a range of nontypical classroom situations, have yet to yield a sufficient body of diverse examples of teaching for scientific inquiry. Research studies documenting classroom-based scientific inquiry should include a wider range of pedagogical exemplars, rich student learning artifacts, and outcomes than what is commonly presented in the research literature. Second, an inadequate set of visions of best practice suggests the possibility that our current view of the "successful implementation" of inquiry science is based on narrow and limited criteria. More research that critically explores what it means to be "successful" among a wider range of classroom contexts and audiences could lead to an expanded understanding of classroom-based inquiry. Third, if one of the primary goals of science education research is to demonstrate evidence of science literacy for all, research must examine the problem of successful science teaching in varied learning environments reflective of the diverse conditions and contexts prevalent in contemporary schools. Expanded and comparative studies are needed that represent many classroom settings; otherwise claims of scientific literacy for all remain unsubstantiated.

\section{THE KIDS AS GLOBAL SCIENTISTS CURRICULAR INNOVATION}

The Kids as Global Scientists Weather (KGS) Program consists of a systematic, curricular approach to fostering students' deep conceptual understanding of weather content through the use of a suite of learning tools designed specifically with inquiry science in mind. This suite of tools includes the KGS curriculum, the KGS software, and, among local teachers, a systematic structure of teacher professional development.

Several features make the KGS Weather program a novel and innovative approach towards inquiry learning. These include 8 weeks of coordinated activities that culminate in inquiryoriented real-time predictions; the use of real world scientific phenomena as the context for students' engagement with scientifically oriented questions; and a set of software tools that guide students towards salient data and productive construction of explanations with others. 


\section{The Inquiry Curriculum and Real World Phenomena}

The KGS inquiry activities support students' knowledge development through focused guidance in data collection, data analysis and critique, analysis of current events with scientists and peers online, and predictions about tomorrow's weather. In the program, students build on and expand their own questions in science (Bransford et al., 2000), and embrace challenging authentic science situations (Lee \& Songer, in press) as they are guided by support structures that allow these challenges to be realized (Bransford et al., 2000). Students' questions vary a great deal in complexity and topic. Sample student questions from this run include

What does hail feel like?

Dear [weather specialist]. I am new at this. I have a question about tornadoes. How do tornadoes form over the water? And what do they do over the water?

How many inches of snow equals one inch of rain?

Why does precipitation fall?

Through activities that provide systematic exploration of local and national current winds, temperatures, and developing storms, students are guided towards understandings that both foster acquisition of the weather concepts and lead to students' increasing ownership of their own knowledge development.

The study of actual storms provides an essential context for the development of rich understandings of atmospheric science. In many KGS classrooms at any given time, live storms are studied and discussed with experts online. When Internet connections are down or unreliable, teachers can utilize archived storms, present on the CD-ROM in the same interface, for the same exploration of patterns and questions. In this way, the KGS program provides an Internet-based curricular program that is "more reliable than the Internet itself" (Songer \& McDonald, 2001), an important feature of school curricula that use Internet resources for inquiry explorations. The curricular sequence culminates in the real-time forecasting of weather in target cities across the country, modeled and guided by online content experts and peers in target cities (Songer et al., 2002). Previous research demonstrates that the organization of a sequence of activities that are intended to promote the development of deep foundational knowledge and essential inquiry thinking through the study of actual storms leads to strong learning outcomes (e.g. Songer et al., 2002). For more information on the KGS learning approach and curricular sequence, see Songer (1998) and Songer et al. (2002).

\section{Software Tools}

KGS software consists of a CD-ROM that houses both archived imagery and a web browser for the retrieval of real-time imagery, as well as a separate Internet-available, webbased threaded discussion board. Students and weather scientists retrieve current weather data from around the United States in real-time. Learners are presented with an interface format that allows them to select and superimpose salient weather data of their choosing, presented in multiple, linked representations specifically designed to support data analysis and the forecasting of weather conditions. The web-based threaded discussion board facilitates discussions of students' and teachers' questions about current events, storms, and predictions of weather in focused cities. For more information on the KGS software see Songer and Samson (2000). 


\section{Inquiry Goals}

Through several rounds of research-based iterative refinement, the KGS curriculum innovation, including curricular activities and software, has been developed and improved towards the systematic promotion of two essential features of classroom inquiry (National Research Council, 2000):

a. Learners formulate explanations from evidence.

b. Learners connect explanations to scientific knowledge.

The KGS program fosters the development of explanations through the 8 weeks of inquiry activities that sequentially encourage students to collect, reflect on, and develop explanations of patterns observed using their own and others' local and national weather data. Using the KGS CD-ROM to retrieve and analyze weather data in a learner-focused interface, students are guided to connect their developing explanations and analysis to current weather events with the help of teachers, peers, and online scientists. Connections are also fostered through guided predictions and evaluation of tomorrow's weather on selected cities around the United States.

\section{Towards Large-Scale Impact}

The KGS innovation is one of a suite of reform-orientated science programs that is designed to foster inquiry thinking among middle school science students and teachers. Research documents the crucial role classroom teachers play in the success or failure of educational reforms (Ball \& Cohen, 1996; PCAST report, 1997; Slavin, Dolan, \& Madden, 1996). The history of school reform also documents that, though many curriculum reform programs realize significant learning outcomes with a handful of self-starter teachers, very few initiatives have lasting impact beyond these self-starters. When reforms became selfsustaining over longer periods of time, it is often through specific mechanisms to build foundational support structures that can provide long-term, systemic support to teachers and classrooms over several years.

Numerous small-scale reform projects and more comprehensive systemic reform initiatives in science classroom have advanced understanding about teacher practices that promote inquiry science among K-12 learners (see for example, White \& Fredricksen, 1998; Lehrer et al., 2000; Metz, 2000). Often learning gains are realized among relatively limited numbers of students, and in small numbers of classrooms. Under increasing pressure to expand the impact of these model programs from hundreds to many thousands of children, policymakers and funding agencies are asking such groups to conduct research on transforming a project that demonstrates convincing results with a handful of classrooms into one that is successful with many diverse classrooms. In part because few good examples of large scale impact are available, many researchers struggle with questions concerning how locally successful curriculum reforms might have broader, larger "scale" impacts beyond a limited set of self-starter teachers. One common barrier towards realizing large scale is the lack of consensus about what it means to successfully scale an innovation. In other words, once a program is characterized as a success on a small scale, which features of the innovation should be replicated in the various new classroom locations? Which features of the innovation should be adjusted to the new target audience or context? What research methods are best suited to understand the complexity of this process? The success KGS has enjoyed in differing school contexts creates research opportunities that help us address these questions. 
Our research to expand an understanding of classroom inquiry begins with our work to recruit, support, and characterize classroom audiences and learning environments that extend beyond the usual "self-starter" teachers and well-supported school contexts. We looked for teachers whose working conditions discouraged attempts to seek out innovative science education reform programs. Such teachers were found in resource-challenged urban school districts. The result of these efforts led to the characterization of two different types of teachers, what we call maverick and urban teachers.

The Maverick Approach. Many reform programs typically draw teachers from school districts in which volunteer participants are attracted by word-of-mouth, direct solicitation from project organizers, or through Internet queries or advertising. Often times, these teachers have a common, self-motivated initiative to seek out and experiment with innovative curriculum reforms. Like many others, the KGS research group worked with such maverick teachers for several years. During this time, we conducted a range of research studies on KGS middle school inquiry science programs distributed across handfuls of schools across the United States, largely subscribing all classrooms and teachers that came to us through our website or other volunteer means. Using this approach, we demonstrated significant knowledge gains on weather content with each program run (i.e. Songer, 1998; Songer et al., 2001) as we realized increased numbers of students and schools each year. With each run of the program, we gathered data from teachers allowing us to formulate the following general characteristics of our maverick teachers:

- The teacher is an early adopter of other reform programs and is therefore experienced and comfortable with risk-taking and overcoming small or large obstacles common in new innovations.

- The teacher enjoys a great deal of flexibility and autonomy in decisions over pedagogy and curricular implementation, including less pressure from standardized tests or curriculum objectives than is present in most urban schools and/or schools at risk for school failure.

- The teacher has key support structures in their building, including strong administrative and technological supports.

Expanding Our Research Beyond Mavericks. Reflecting on our participant data through our 1998 programs, we realized that, while our impact with maverick teachers was resulting in increased numbers of participants each year, we were not attracting very many students representing either low SES or high minority populations. Recognizing the need for systematic research among a wider set of student populations, we began to explore support, professional development, and recruitment efforts to attract schools that serve minority, urban, and/or high poverty populations, and began to shift our research towards a focused examination of the barriers to inquiry pedagogy in urban classrooms. As a part of this research, we studied the kind of teaching that appears prevalent in urban classrooms, what Haberman (1991) has termed the "pedagogy of poverty." Haberman (1991) describes the pedagogy of poverty as a set of directive, controlling teaching practices that commonly exist in urban classrooms and can be at odds with efforts to foster inquiry science (Songer et al., 2002).

The prevailing norms of instruction in many urban schools combine with chronic conditions of limited resources to discourage maverick urban teachers who might otherwise have the time and support to seek out innovative science inquiry programs. With the help 
of a cooperative professional development support structure between the Detroit Public Schools and the University of Michigan, KGS has secured a presence in numerous urban classrooms and the results so far have been quite promising. In one recent study, all urban KGS classrooms demonstrated significant gains from pre- to posttests designed to measure content and inquiry in atmospheric science (Songer et al., 2002). Research into the success of programs like KGS in urban classrooms is helping us to understand specific mechanisms that challenge the pedagogy of poverty (Haberman, 1991; Songer et al., 2002). Although this research facilitated the characterization of a range of inquiry science profiles among urban KGS classrooms, our research has not yet allowed us to compare populations of urban and maverick teachers, or to compare student learning outcomes among students of urban and maverick teachers.

Professional Development and Support with Urban Teachers. The support and professional development for urban KGS teacher-participants is based on a model by Krajcik et al. (1994), and is used in the coordinated effort of a number of university project teams. These teams consist of university personnel who design inquiry-focused middle school curriculum materials and support teachers as they enact science units that fall under the umbrella of the Center for Learning Technologies in Urban Schools (LeTUS) (Blumenfeld et al., 2000). The professional development framework is made up of four components: "Collaborative construction of understanding; Enactment of new practices in classrooms; Reflection on practice; and Adaptation of materials and practices" (Blumenfeld et al., 2000, p. 151) or CERA.

The CERA framework guides the five strands that make up the year-long KGS professional development effort. Teachers attend summer workshops and Saturday work sessions, participate in an online teacher message board, have access to in-class support during enactment, and use curricular materials provided by the KGS team. The summer workshops last 2 weeks and focus on all aspects of the enactment, including productive use of technology, weather content, hands-on activities, and the inquiry-based pedagogical framework. Complementing the summer workshop are Saturday work sessions occurring once a month through the fall and winter during which teachers and university personnel focus on topics of interest collaboratively generated among university and school-based project participants. These work sessions allow teachers to plan together, with help and input from the university team and other teachers, and develop solutions to enactment difficulties they have had in the past, or ones they foresee in the year to come.

Once teachers begin teaching the KGS curriculum in early spring, university researchers make regular visits to teacher-participants' classrooms to provide logistical, technical and pedagogical support. Teachers also have access to an online teacher message board for discussion with other teacher-participants, university support, and weather content specialists. Finally, the curriculum materials themselves perform an educative function by providing guidance for planning and enactment of the curriculum, as well as indicating connections to national standards (Ball \& Cohen, 1996). Altogether, these various supports create an environment where teachers are participating in all components of the CERA framework simultaneously. They adapt curricular materials to their unique teaching situations in collaboration with university researchers, content experts, and other teachers in their local areas and across the country. At the same time, they reflect on this process through both formal and informal interactions within a broad KGS community.

The KGS program of professional development benefits urban teachers in several important ways. This model of support enhances the teachers' abilities to 
- Utilize existing structures and individuals, such as professional development workshops and local colleagues, as essential supports for on-going trouble-shooting and sustainability.

- Collaborate and learn with a group of teachers who have a wide range of profiles relative to innovations, including early adopters, second level adopters, and reluctant adopters.

- Work with a wide range of student populations, including many students at risk for school failure.

In this way, KGS attempts to make it easier for teachers in urban schools to participate in science inquiry reform projects. By lessening the resource and support gap, and by promoting a curriculum that provides first-hand experience with inquiry models of science teaching, the KGS program empowers urban teachers to participate in science education reforms that have traditionally appealed mostly to maverick teachers.

\section{PARTICIPANTS, INSTRUMENTS, AND RESEARCH METHODS}

\section{Program Participants}

Over the past several years, the KGS program has been utilized by large numbers of schools, students and scientists, as well as increasing numbers of diverse schools. At present, a majority of our school sites are those considered highly diverse, serving populations of greater than $50 \%$ minority students, a population that has not commonly experienced hightechnology inquiry science programs. More details on how our program has expanded are available in the Results section.

In the focus year, the KGS Weather program (Songer et al., 2000) was implemented simultaneously in 230 classroom settings with approximately 230 teachers (some of whom taught multiple classes) and 13,000 fourth-ninth grade students from 40 states. In addition to ethnic diversity, the classroom populations were diverse in type of community setting and Internet reliability. While the largest percentage of classrooms were in urban settings $(41 \%)$, many schools were located in rural $(31 \%)$ and suburban $(28 \%)$ locations. By teacher self-report, Internet reliability was largely unreliable, with $47 \%$ of teachers describing their computer reliability as poor and only $18 \%$ describing it as very reliable. In this particular program run, then, a diverse group of students and teachers participated. However a common profile of a KGS site was an urban classroom with a high percentage of minority students and poor Internet reliability.

The research described in this paper will focus on only a subset of the total KGS participants. To address questions characterizing maverick and urban teachers, we gathered data from 57 KGS teachers: 17 urban teachers within Detroit Public Schools, and 40 maverick teachers distributed across the United States. Detroit Public Schools (DPS) is a large district with a population of $96 \%$ minority students of which over $70 \%$ are eligible for free or reduced lunch.

To address questions on the details of student learning and teacher beliefs within focus classrooms, data were collected from seventeen teachers and their students, from which five classroom groups were chosen for detailed analysis. The students from the five selected classrooms were chosen both because they were all of the same age (sixth grade) and they demonstrated significant content gains from pre- to posttests measuring weather content and inquiry. Because of these demonstrated achievement gains, all five selected classrooms were defined, for purposes of this study, as "successful." Of the five focus groups, two were chosen as representative of successful maverick groups, and three were chosen as representative of successful urban groups. 


\section{Instruments}

Data were collected and analyzed on two populations of individuals: A large sample of maverick and urban teachers $(N=57)$, and a small sample of maverick and urban teachers $(N=5)$ and their students $(N=225)$. Data collected from the large sample included: preprogram registration surveys, and postprogram teacher surveys. These data were used to characterize maverick and urban teachers' demographic and background characteristics, beliefs about science teaching, reactions to the KGS program, and views on support of the KGS program in their classroom. Data collected from the small sample included: teacher interviews, teacher registration and postprogram surveys, student pre- and posttests measuring content and inquiry, teacher logs and classroom observation forms (local teachers only). These data were used to characterize the nature of student learning outcomes, including both multiple-choice and open-ended measures of scientific knowledge and inquiry thinking, as well as details on teacher beliefs, reflections on KGS enactment, and reflections on the support of reform programs such as KGS in their classroom.

Teacher Registration and Postprogram Surveys. Teacher self-report information was gathered from 57 teachers at both the beginning and the conclusion of the 8-week program. At the onset of the program, detailed information was obtained about the population of students, the nature and setup of technology in their classroom, their previous experience with inquiry curricular programs and their views about inquiry teaching. The postprogram report asked teachers to respond to several classroom scenarios concerning their preferred teaching approach, detailed information about the amount and choice of KGS activities they implemented, and a range of questions focusing on their impressions of the learning achieved by their students.

Teacher Interviews. At the completion of the program detailed teacher interviews were conducted with all focus teachers from the small sample. Interviews were conducted inperson with the three focus urban teachers, and by telephone for the two focus maverick teachers. The interviews concentrated on teacher support structures, motivation and expectations, challenges and successes, evaluation of student learning, discussion of fostering inquiry, resources utilized, and descriptions of successful and unsuccessful teaching experiences with the KGS program. The interviews lasted about 35 min each. As in previous years, the interviews were semistructured (Merriam, 1998) and were adapted in concert with current research in teacher reflection and learning (Yorker \& Songer, 1999). All interviews were transcribed in full for further analysis.

Classroom Observation Forms. Data gathered during classroom enactment of the KGS program were utilized as a secondary data source only, to clarify patterns observed in student learning outcomes or teacher interviews. For observations, one or two researchers were assigned to each of the urban teachers for regular observations, at least once per week, during the program run. Researchers gathered a total of 119 observations in the classrooms of 17 different urban teachers. Observations were recorded via the KGS Classroom Observation form developed from Emmer (1986) for coding task structures to track elapsed time, participants, classroom descriptions, and activities performed in classrooms.

Student Pre- and Posttests. Student pre- and posttests were collected and analyzed on a total of 225 students, those students of the five focus teachers in the small sample. One important means of characterizing student learning is through the use of a rich set of 
assessment instruments that include released standardized items as well as open-ended and interview assessment items. In this study, participating students were given written preand postassessments consisting of 21 items measuring content and inquiry understandings. Items included 14 multiple-choice, 6 open-ended, and 1 pictorial question. As in previous years, multiple-choice items included released National Assessment of Educational Progress (NAEP) items measuring understandings of temperature, weather data collection, chart interpretation and inquiry. Multiple-choice items also included four modified Michigan Education Assessment Program (MEAP) items on fronts, pressure and weather interpretation.

Evaluating student inquiry understandings through traditional, easily scored, and widely available assessment materials is difficult due to the sometimes glaring mismatch between standardized test items and the sophisticated kinds of thinking characteristic of scientific inquiry. In previous years we utilized standardized test items such as the following as one indication of students' developing ideas about inquiry thinking.

"Hypotheses are ...

a. ideas that can be tested

b. facts about science

c. observations of nature

d. results of experiments"

(Owens, 1992)

Recognizing that a correct response on this item requires only a very simplistic definitional understanding of inquiry thinking highlights how such items may not be useful in capturing the kinds of complex thinking students engage in as a result of our 8 weeks of activities, such as making and justifying the prediction of the location of a front passing over Chicago. Therefore we developed new and expanded open-ended items that are more helpful in gauging the thinking that supported students' responses. For example, students are asked to explain their reasoning related to relationships between air pressure and storms, or to describe what causes rain at the boundary between warm and cold air. Asking students to generate explanations is not only a stronger match to the inquiry activities in the KGS program, but a more telling indicator of the kind of higher-order thinking KGS inquiry activities are intended to foster. Expanded items included questions that required both an understanding of foundational weather content and an understanding of inquiry skills, such as prediction making, in order to achieve full credit. Figure 1 displays one multiple-choice and one open-ended item from our pre- and posttest. The open-ended item was designed by research staff to match learning activities on prediction making about passing cold fronts.

\section{Data Analysis}

Analysis of Pre- and Posttests. All 21 items were coded for all 225 focus students. The 14 multiple-choice items were worth 14 possible points, and the seven open-ended items were worth two points each for another 14 possible points. For the multiple-choice items, repeated measure ANOVAs were used to illustrate changes in students' content knowledge development from pretest to posttest by class. Research staff developed qualitative coding rubrics for the open-ended items, resulting in three-level rubrics for each open-ended item. In coding each item, a team of three researchers met several times to determine interrater reliability on qualitative items of $91 \%$. A sample rubric for one open-ended item is available in Figure 1. 
MULTIPLE CHOICE (from Owens, 1992; underlined choice is correct)

1. Which of the following should a science class do to find out which wind direction is most common during times of cloudy skies and wet weather in their town?

a. Check a weathervane, thermometer and barometer daily

b. Make a chart of the different cloud formation shown in an encyclopedia

c. Keep a record of daily rainfall for an entire year

d. Record wind direction, cloud conditions, and rainfall daily for at least four months

\section{OPEN ENDED}

Study the following weather maps around Michigan on April 1 and 2 and answer these questions.
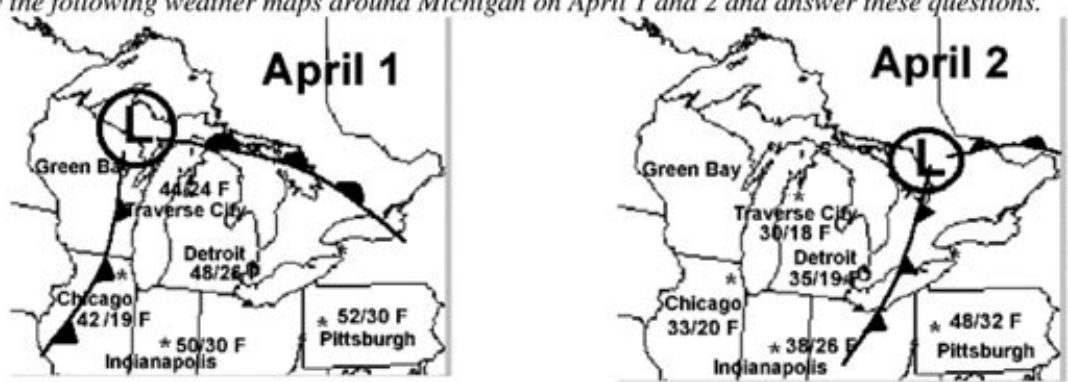

After studying the weather maps, Juan said that the weather in Pittsburgh would be much cooler on April 3rd. Give two pieces of scientific evidence that Juan should use to support his prediction.

(1)

(2)

\begin{tabular}{|l|l|}
\hline Code & Criteria \\
\hline 2 (Scientific) & $\begin{array}{l}\text { - Cold front approaching/passage over Pittsburgh } \\
\text { - Temperature drop occurring in other cities such as Detroit, } \\
\text { Indianapolis, etc. }\end{array}$ \\
\hline 1 (Partial) & $\begin{array}{l}\text { At least one of above or two of the following weaker evidence: } \\
\text { Low pressure passage } \\
\text { - Warm front passage } \\
\text { - Temperature change in Pittsburgh for two days }\end{array}$ \\
\hline 0 (Naïve) & \begin{tabular}{l} 
One of above weaker evidences \\
\hline
\end{tabular} \\
\hline
\end{tabular}

Figure 1. Sample KGS assessment items including both multiple-choice and open-ended components.

Analysis of Teacher Surveys. Statistical analysis was utilized to determine trends among all the 57 teacher surveys collected, including 17 surveys from urban teachers and 40 surveys from maverick teachers.

Analysis of Teacher Interview and Classroom Observations. Teacher interview and classroom observation data were used as secondary data to support and elaborate results from the primary data sources of teacher surveys and student assessments. A total of 20 teacher interviews were conducted and transcribed, but only those of the five focus teachers were analyzed in detail. Of the total sample of 119 classroom observation forms, observations from only the three local focus teachers were analyzed in detail. For coding teacher interviews and classroom observation forms, researchers adapted the qualitative analysis protocol of Chi (1997). As with previous data, we followed Chi's eight functional steps for coding qualitative data including sampling the data, reducing the data, and choosing a 
coding scheme that in our case was the development of categories (Chi, 1997). Our categories were consistent with the KGS qualitative rubric (Songer et al., 2002) that characterized the nature and duration of activities implemented, roles assumed by teachers and students, state of technological connectivity, and use and characterization of artifacts developed by students during the observation period.

\section{RESULTS}

This study set out an ambitious research agenda in the ways it investigates multiple questions raised by recent research in science education. This study looked at examples of classroom-based successful science inquiry that utilized innovative learning technologies, in very different school contexts, and with an eye towards developing an expanded and more comprehensive vision of inquiry science, especially as that vision might inform the discussion on how to scale up effective science education. Arguably, what this study lacked in precision is made up in scope. The study pushes traditional boundaries of science education research in an attempt to produce results that are meaningful in a complex policy and educational reform environment calling for "science literacy for all." In this section, we address these results by first describing the expansion of KGS into more classrooms and to a wider range of classrooms. Then we provide a description of the characteristics of maverick and urban teachers, and a comparison of five focus classrooms. Finally, we detail the student learning outcomes apparent in this research.

\section{Expanding KGS Classroom Environments}

Over the past 5 years, KGS has been implemented in a steadily increasing number of schools. In this program run, the number of total participants, including students, teachers, and scientists, was estimated at 13,000. This number demonstrates a level of impact and scale uncommon among many of the research projects typical in the field. Table 1 displays the spread of the program into more classrooms and its use by increasing numbers of participants, including a high number of participants in 1998 when two programs were run in 1 year.

Beginning in 1999 we began to recruit urban teachers in order to expand our research impact beyond a narrow subset of learners and classroom contexts. Table 2 demonstrates the significant shifts in population of KGS learners, from only 8 schools with high levels of minority students in 1996, to 59 schools with this population only 4 years later. As our recent research continues to demonstrate significant learning gains in a large majority of our sites (see for example Songer et al., 2002), we believe these numbers suggest both successful impact with many learners, and successful impact among a diverse set of learners.

\section{Who Are Our Maverick and Urban Teachers?}

As a first step in understanding the learning outcomes in our focus classrooms, we began with research analysis that would help us more fully characterize some of the general

\section{TABLE 1}

\section{One Sky, Many Voices Participants, 1996-2000}

\begin{tabular}{lrrrrrr}
\hline Participation & 1996 & 1997 & 1998 & 1999 & 2000 & Total \\
\hline School sites & 60 & 150 & 350 & 114 & 230 & 904 \\
Students & 1,500 & 6,000 & 20,000 & 11,000 & 13,000 & 51,500 \\
Scientists & 32 & 60 & 40 & 45 & 65 & 242 \\
\hline
\end{tabular}


TABLE 2

Number of Diverse Schools as Participants, 1996-2000

\begin{tabular}{ccccccr}
\hline Minority Population (\%) & 1996 & 1997 & 1998 & 1999 & 2000 & Total \\
\hline $0-19$ & 17 & No data & 44 & 38 & 101 & 200 \\
$20-50$ & 6 & No data & 14 & 31 & 44 & 95 \\
More than 50 & 8 & No data & 17 & 65 & 59 & 149 \\
\hline
\end{tabular}

characteristics of the two types of focus teachers in our study. While we had gathered preliminary data on maverick teachers before, we had never gathered detailed information on both maverick and urban teachers for purposes of characterization and comparison. We asked, what are the general beliefs, learning contexts, and backgrounds of the larger populations of maverick and urban teachers, and how are they similar or different from each other? Patterns from all teacher surveys and teacher interviews were explored in the areas of teachers' backgrounds, pedagogical beliefs and values, and a self-evaluation of their experience with several learning features of the KGS program. While teachers provided information on a total of 78 items from these data sources, data from a total of 19 items provided valuable comparative information.

Maverick Teachers. Table 3 presents 11 items related to teacher characteristics. On demographic and background measures, maverick teachers share characteristics that signify a type of teacher that stands apart from their urban counterparts. Concerning ethnicity, maverick teachers were largely Euro-American. Judging by self-reports of educational background, maverick teachers had relatively strong science content backgrounds, with $48 \%$ of mavericks majoring in science in college. While a majority of mavericks taught in public schools $(70 \%)$, a little less than a third taught in private or home-schooled environments.

Moving beyond demographic and background characteristics, maverick teachers reported beliefs about science teaching that were largely consistent with an inquiry-based reform

\section{TABLE 3}

Teachers' Characteristics, Backgrounds, and Instructional Freedom (Based on Self-Report)

\begin{tabular}{lcc}
\hline \multicolumn{1}{c}{ Teacher Characteristics } & $\begin{array}{c}\text { Urban Teachers } \\
(\%)\end{array}$ & $\begin{array}{c}\text { Maverick Teachers } \\
(\%)\end{array}$ \\
\hline Female & 59 & 55 \\
African-American, Hispanic, & 53 & 7 \\
$\quad$ and other non-White & 100 & 70 \\
Teach in public schools & 18 & 48 \\
Science majors & 47 & 48 \\
See themselves as facilitators & 65 & 35 \\
Believe students should master a few complex & & 83 \\
$\quad$ ideas (depth vs. breadth) & 82 & 43 \\
Value real-time data & 18 & $67 / 33$ \\
Value small, self-paced groups & $88 / 12$ & 12 \\
See reliable Internet access as essential/ & & High \\
$\quad$ have that now & 24 & \\
Dissatisfied with technical support at my school & Low to average & \\
Instructional freedom & &
\end{tabular}


orientation. As illustrated in Table 3, about half of the maverick teachers describe themselves as facilitators in their science classrooms, and $43 \%$ state that they were very comfortable having a variety of small, self-paced student activities going on at the same time during the KGS program. One maverick teacher explains that he was able to guide various different activities simultaneously in part because the students were well behaved and on-task,

Maverick 1: Students were self-directed, eager to come to class, settle down and work.

Turning to more specific questions about their experiences with KGS, maverick teachers rated several features of the program as particularly helpful. As shown in Table 4, several maverick teachers valued the KGS program features as they provided guidance and support for students' helping and learning from each other (45\%), a break from more traditional learning $(60 \%)$, and access to new individuals and resources $(37 \%)$. A large majority of mavericks (83\%) also felt it was important for their students to use real-time data in studying science, as complexity and uncertainty were part of problem solving in science. Many mavericks praised the forecasting activity that concluded the program because of the manner in which it fostered inductive reasoning and connection making among concepts,

Maverick 2: I liked the ability to use inductive reasoning in a structured way through the activities focusing on using the weather maps to make predictions on humidity and temperature.

Maverick 3: [I liked the] real-time activities. I liked the flexibility to use actual data at any time to show and review the movement of weather patterns and how each different aspect were associated to other ones (example: fronts and precipitation).

In data not represented in the tables, many maverick teachers also declared the hands-on activities, such as "Cloud in a Bottle," and the collection of 2 weeks of local weather data as their favorite activities. In fact, a large percentage of mavericks mentioned that they spent

\section{TABLE 4}

Teachers' Beliefs Concerning the Value and Challenges of KGS Features by Teacher Group (Based on Self-Report)

\begin{tabular}{llc}
\hline \multicolumn{1}{c}{ Teacher Beliefs } & $\begin{array}{c}\text { Urban Teachers } \\
(\%)\end{array}$ & $\begin{array}{c}\text { Maverick Teachers } \\
(\%)\end{array}$ \\
\hline $\begin{array}{l}\text { Students help one another more during } \\
\text { the KGS program }\end{array}$ & 65 & 45 \\
$\begin{array}{l}\text { Students writing quality is better using } \\
\text { the message board }\end{array}$ & 41 & 12 \\
$\begin{array}{l}\text { Students obtain access to new information } \\
\quad \text { and people }\end{array}$ & 53 & 37 \\
$\begin{array}{l}\text { Students' attendance is high during KGS } \\
\begin{array}{l}\text { Computers provide a welcome break from } \\
\text { more traditional learning }\end{array}\end{array}$ & 24 & 12 \\
$\begin{array}{l}\text { Not difficult to integrate computer activities } \\
\text { into my lessons }\end{array}$ & 14 & 60 \\
$\begin{array}{l}\text { Somewhat difficult to settle students } \\
\quad \text { down after KGS }\end{array}$ & 94 & 50 \\
$\begin{array}{l}\text { Somewhat true that too many students need } \\
\text { my help at the same time }\end{array}$ & 41 & 27 \\
\hline
\end{tabular}


more time than suggested on these activities (30\% spent more time than suggested on the hands on experiments, and $45 \%$ spent more than suggested time collecting local weather data). One teacher explains the manner in which collecting and analyzing data provided the inquiry experiences she valued for her students,

Maverick 4: We spent a lot of time collecting and analyzing data. We ended by comparing data with other schools during the same time period. Overall it was a wonderful learning experience for my students. Keep up the good work!

A final characteristics shared by many maverick teaches was a belief that they were well supported in their attempts to implement inquiry science teaching. Maverick teachers largely describe their administrative support as strong, and the degree of instructional freedom as high. Concerning support for technology, only $12 \%$ of mavericks indicated they were dissatisfied with the technology support in their building, and several others commented on the strong support materials that were built into the program, including the CD-ROM with built-in archived storms and online weather experts provided by the KGS program.

Maverick 5: I am fully supported here in all aspects. Archived data was a life-saver on the days Internet connections were down.

Maverick 6: Weather specialists were fantastic. My students were very pleased with the respect that their questions were given.

Although our maverick teachers do not fit any one profile, a reasonable composite profile of one of our maverick teachers is a White female, with an educational background in science, who is teaching in a school with strong administrative support and good technology, though not necessarily a fast Internet connection. Her class size would hover around 27 or 28 students. This maverick teacher likely sees herself as a facilitator of learning, and is enthusiastic about the hands-on, real-time, and forecasting features of the KGS program.

Urban Teachers. The urban teachers in this study differed from their maverick counterparts in their demographic profiles and educational background. As shown in Table 3, urban teachers taught in inner-city public schools within Detroit, Michigan, and over half were non-White ethnic minority (African American or Latina/o-Hispanic or other non-White). In contrast to the maverick teachers in this study, only a small percentage (18\%) of urban teachers had undergraduate majors emphasizing science disciplines, and therefore most urban teachers do not have the content background preparing them to teach science. This finding is consistent with other studies that document that a small percentage of urban teachers are trained in the content areas in which they teach (Teel et al., 1998). Class sizes in urban teachers' classrooms tended to be large, with nearly half of them mentioning that they had a class size of 31 or larger, and in one case class size approached 40 students.

Like many of the maverick teachers featured in this research, urban teachers reported beliefs about teaching science that are consistent with an inquiry-based reform approach (see Table 3). In this case, these urban teachers may not represent typical urban teacher beliefs about teaching, for many of the urban teachers in this study had significant exposure to inquiry science professional development via collaboration between Detroit Public Schools and the University of Michigan. Concerning pedagogy, a majority of urban teachers $(65 \%)$ expressed a preference for inquiry pedagogy over more direct and teacher-centered forms of teaching. Results from the teacher survey indicated that most urban teachers valued students' mastery of a few complex ideas rather than a more cursory review of numerous science 
topics. Interestingly, only $35 \%$ of maverick teachers answered the same "depth vs. breadth" question in the same way. Therefore, although urban teachers expressed a commitment to science inquiry teaching at a level that matched or even exceeded that of the maverick teachers, an important difference emerged regarding the kinds of classroom activities that support such instruction. Here, only $18 \%$ of urban teachers valued small, self-paced group instruction compared to $43 \%$ of the maverick teachers. The difference may be explained by the challenges associated with the large class sizes typical in urban schools. As one urban teacher explained,

Urban 1: When we did the activities, we did it as a whole group...I find that in this, it is really hard to have them [different small groups] do a different activity.

As a result, we observed many urban teachers carrying out KGS inquiry activities in supportive ways, but with the class participating as a whole class rather than individual small groups.

Table 4 presents several learning dimensions of the KGS inquiry learning environment that urban teachers found favorable to students' learning, several of which were not seen as so valuable by maverick teachers. First, many $(65 \%)$ urban teachers felt that students helped each other more in the KGS program than in other science programs. One urban teacher explained the role of the cooperative learning in facilitating rich conceptual understandings among his students,

Urban 2: I like the forecasting activity mainly because it brings everything together... When they were doing forecasting it aided in cooperative learning because a lot of time they had to explain their prediction and together they came up with a better answer than one person would have individually.

Another urban teacher highlighted the value of student collaboration in KGS,

Urban 3: By allowing them to discover things and to build things together I think it's an excellent way for them to learn.

Urban teachers also pointed to the ways in which KGS helped improve their students' writing and facilitated on-task behavior. More specifically, features such as the KGS message board, web-based weather information, and access to weather scientists set KGS apart from other science inquiry programs these urban teachers had experienced recently. As one urban teacher explained,

Urban 4: The advantages are tremendous. We all need to get online, we all need to be computer literate ... we even had the opportunity to talk to a weather specialist. I mean that is incredible ... it just keeps the students so busy all the time... we lose the kids when we don't have enough to do.

Perhaps as a result of these differences, urban teachers noticed more on-task student behavior relative to other science programs. As a result, classroom management difficulties were lessened. One urban teacher explained this dynamic,

Urban 5: Yeah, I think that bad behavior diminished [with KGS]. We don't have much bad behavior when we are using this program ... kids are engaged. Dr. C [the principal] came in one time... they are challenging a lot of kids! She came in here and she was surprised. They were really engaged. 
A related management difference mentioned by a fourth of the urban teachers was a noticeable increase in attendance during the KGS program as compared to other science programs that year. Another KGS benefit mentioned by urban teachers that was shared by maverick teachers included a recognition of the value of student access, forecast, and use of real-time data for build understandings of weather concepts $(82 \%)$. One urban teacher elaborates on this value for learning science,

\begin{abstract}
Urban 6: When they make a forecast or prediction or try to find out what the weather is like in a certain place they have more information at their hands than if they didn't use those kind of tools. I've taught weather for nine years and without the maps and without the real-time data it really limits the study because they don't understand what's happening ... because they only see maybe Detroit.
\end{abstract}

A final set of urban teacher characteristics is clustered around issues of support. In adopting the KGS inquiry science approach, urban teachers found assistance in three forms: technology support, pedagogy and content support from KGS, and administrative support within their schools and the district. Compared to maverick teachers, urban teachers experienced more limited access to reliable technology and technology support within their schools. Only $12 \%$ of the urban teachers reported that they enjoyed reliable Internet access. As one urban teacher explained,

Urban 7: The biggest obstacle was the computer online. Sometimes we just couldn't get online at all ... other times it took so long for it to come on that it was difficult for them to remain on task.

Besides Internet connections and computer hardware, urban teachers were twice as likely to be dissatisfied with the level of technology support within their buildings. To some extent, features of KGS helped urban teachers respond to these perceived inadequacies. The resource challenges of urban schools meant that the face-to-face contact with project staff and features of the KGS curriculum (e.g., archived data on CD, and on-line assistance of weather specialists) were more crucial for urban teachers.

Urban 8: [Project] support in the classroom was excellent as well as the Saturday inservice.

[All of these were] very helpful and informative.

Finally, urban teachers dealt with concerns about administrative support that were less frequently voiced by maverick teachers. Urban teachers faced significant pressure from administrators to teach towards state-sponsored high-stakes standardized tests. As testing took priority over all other activities in many of these schools, test-prep time not only reduced the amount of time available for in-depth inquiry programs like KGS, but it supported test-taking skills and memorization that ran counter to the learning approach advocated in inquiry programs. In the words of one urban teacher,

Urban 9: [My unit head] is not completely satisfied with any of these programs ... She feels we should be MATTing or MEAPing [i.e. preparing for high-stakes state tests]. Doesn't matter what program you use.

Like maverick teachers, urban teachers were a diverse population within themselves. Nevertheless, a reasonable composite profile of an urban teacher might be an AfricanAmerican female with a background in Social Studies. While she benefits from professional 
development and some technology support through the KGS program and the professional development of LeTUS, by and large her support structures are thin, including an unreliable network connection and a low level of building support needed to carry out the full 8-week inquiry science program. Her class size is around 35 students, and she has few, if any, prep periods in any given week. This urban teacher would most likely see herself as a facilitator of learning, and be supportive of her students spending longer amounts of time on fewer inquiry science concepts. She would be most pleased with the support provided by the program and staff to help her overcome the challenges she faces in administering a multiweek, technology-rich inquiry science program. She would also value several features of the KGS learning environment. These include the students' own data collection, data analysis and critique, and the real-time and forecasting activities that encourage her students to show up to class motivated to learn and share rich content understandings with each other.

\section{Comparisons of Five Focus Classrooms}

Having reviewed the general characteristics of maverick and urban teacher participants, we now turn to a closer examination of the study's five focus classrooms and teachers. Research questions explored in this section include

a. What are the teacher, student, and learning environment characteristics within the five focus classrooms?

b. What kinds of learning outcomes are observed among these populations of students?

c. How, if at all, do the characteristics and learning outcomes differ among these classrooms of students and teachers implementing the same program at the same time?

Teacher Background and Population Differences. Table 5 displays population and teacher background information for each of the five focus classrooms. These focus classrooms were chosen, in part, because they contained common characteristics, including population (sixth grade), type of school (public), implementation of the full 8-week KGS weather program, and their representativeness of their larger group (urban or maverick).

Beyond these commonalties, several differences are present between the class groups that are also represented in the larger populations. First, the focus students of the urban teachers represent a much wider range of ethnic diversity, and a much lower number of native English speakers, than the focus students of maverick teachers. In some cases these differences were quite substantial. For example, only $38 \%$ of the students in focus classroom Urban A were native English speakers. Class size was another trend common in the focus classroom and in the larger population of KGS sites. Class sizes averaged 31 in focus urban classrooms and 21 in focus maverick classrooms. Differences were noticeable between focus urban and maverick students' use of and access to technology. While $96 \%$ of focus maverick students had computers at home, only $58 \%$ of focus urban students did. Similarly, a much lower percentage of focus urban students used computers every day or reported Internet access outside school. Altogether, the data from the five focus classrooms featured in this research support the general trends and distinctions evident among all urban and maverick students in our study in the areas of ethnicity, native English speakers, class size, and use and access to technology.

Student Learning Outcomes. How did focus students perform on content and inquiry assessments? Following the coding rubrics described earlier, data on student learning were 


\begin{tabular}{|c|c|c|c|c|c|}
\hline & \multicolumn{3}{|c|}{ Successful Urban Classrooms } & \multicolumn{2}{|c|}{ Maverick Classrooms } \\
\hline & A & B & C & A & B \\
\hline Teacher's major & $\begin{array}{r}\text { Math and } \\
\text { science }\end{array}$ & $\begin{array}{r}\text { Elementary } \\
\text { education }\end{array}$ & $\begin{array}{l}\text { Social } \\
\text { studies }\end{array}$ & Education & $\begin{array}{l}\text { Science } \\
\text { education }\end{array}$ \\
\hline Grade & 6 & 6 & 6 & 6 & 6 \\
\hline Region & Urban & Urban & Urban & Suburban & Small city \\
\hline No. of students & 37 & 67 & 80 & 24 & 17 \\
\hline Major ethnic group & $\begin{array}{c}\text { Hispanic } \\
70 \% \\
\text { Black } \\
11 \%\end{array}$ & $\begin{array}{c}\text { Black } \\
39 \% \\
\text { White } \\
33 \%\end{array}$ & $\begin{array}{c}\text { Hispanic } \\
55 \% \\
\text { Black } \\
40 \%\end{array}$ & $\begin{array}{l}\text { White } \\
83 \%\end{array}$ & $\begin{array}{l}\text { White } \\
88 \%\end{array}$ \\
\hline $\begin{array}{l}\text { English as primary } \\
\text { language }\end{array}$ & $38 \%$ & $97 \%$ & $64 \%$ & $100 \%$ & $100 \%$ \\
\hline $\begin{array}{l}\text { Internet access } \\
\text { outside school }\end{array}$ & $68 \%$ & $67 \%$ & $70 \%$ & $92 \%$ & $100 \%$ \\
\hline $\begin{array}{l}\text { Use computer } \\
\text { almost everyday } \\
\text { outside school }\end{array}$ & $49 \%$ & $42 \%$ & $31 \%$ & $67 \%$ & $82 \%$ \\
\hline Computer at home & $73 \%$ & $73 \%$ & $43 \%$ & $92 \%$ & $100 \%$ \\
\hline
\end{tabular}

collected and analyzed from 225 students in the five focus classrooms. Evaluations of science learning were made using instruments consisting of both multiple-choice and open-ended items about weather and scientific inquiry content.

Multiple-Choice Outcomes. Students were evaluated on 14 multiple-choice items representing a range of general weather content information, including the relationship between temperature and precipitation, the characteristics of weather fronts, the review of weather maps to determine where precipitation is occurring, the freezing temperature of water, and the accurate reading of a thermometer. These multiple-choice items were chosen because of their similarity to facts and concepts addressed in the KGS curriculum, and because of their ease of comparison to both previous KGS students' outcomes, and students nationally and internationally. In this study, we utilized multiple-choice items as one means of evaluating students' understanding of general knowledge-level concepts in atmospheric science that are generally associated with more traditional, noninquiry and nontechnology rich science curricula. One example of a multiple-choice item that focused on data collection for wind, clouds, and rainfall is present in Figure 1. Student scores on multiple-choice items are displayed in Figure 2.

As Figure 2 illustrates, all populations of focus students made significant gains on multiple choice from the pre- to posttests except Maverick B, a population that demonstrated a very high pretest score. These results suggest that focus students demonstrated significant understandings of basic knowledge-level weather content after participation in the KGS 8-week program, even in classroom learning environments that had reduced and less reliable access to technology, higher class sizes, and/or many nonnative English speakers. Clearly, these results are promising, particularly the strong effect sizes among urban students. However, these results were not particularly surprising. Previous research on urban students using the KGS program also demonstrated significant 


\section{Multiple Choice Questions}

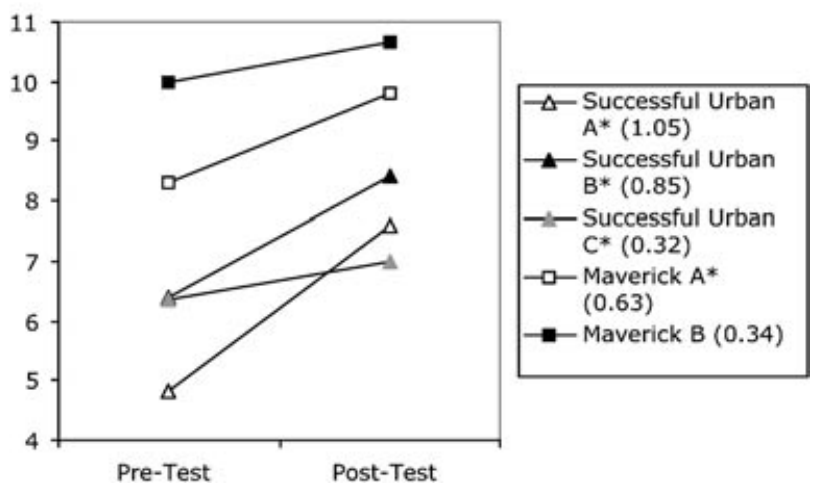

Figure 2. Student pre- and posttest scores (14 points possible) on multiple-choice items $(*: p<.01)$. Note: Effect sizes are in parentheses.

learning gains on more traditional knowledge, multiple-choice content items (see Songer et al., 2002).

Although such gains among urban students are consistent with results evident in earlier research on KGS, previous studies did not provide an opportunity to compare pretest scores and posttest scores between urban and maverick students. In this study, there appears a significant difference between focus urban and maverick students' pretest scores on traditional weather content. More importantly, there was a relative reduction in difference between urban and maverick students' scores on the posttest. This result indicates that urban students had weaker weather-related general knowledge prior to the KGS program. Despite this initial disadvantage, posttest scores are more similar to those of the maverick students than were pretest scores. Urban students using the same KGS inquiry program made substantial gains on assessment of more traditional weather content. In effect, urban focus students realized a level of understanding more similar to their largely White, suburban counterparts, despite relative inexperience both with the science content itself and with inquiry programs such as KGS.

Open-Ended Outcomes. Students were assessed on six open-ended items and one pictorial item. As with multiple-choice items, we utilized open-ended items that were a good match to the KGS program, both in terms of weather content and scientific inquiry. Openended items evaluated a range of learning outcomes that included both more challenging content understandings and science inquiry focusing on weather content, such as using appropriate weather-related evidence to explain the scientific ideas behind cold fronts. Students receiving full credit on open-ended items needed to demonstrate evidence of both scientific inquiry thinking, such as the development of an explanation, as well as understandings of weather content such as the characteristics of a cold front. We designed the open-ended items so that students would need more than a rudimentary understanding of weather content and more than a definitional understanding of inquiry in order to perform well. Figure 1 provides a sample open-ended item and the three-point coding rubric $(0-2)$.

Figure 3 illustrates the student learning outcomes of focus classroom students on openended items. As a comparison of Figures 2 and 3 illustrates, all class average pretest scores were lower on open-ended items than on multiple-choice items. This result suggests that focus students, even those from maverick classrooms, had less prior knowledge with inquiry thinking related to the content area of weather than with more traditional, definitional understandings of weather. In another trend that parallels that seen with the multiple-choice 


\section{Open-Ended Questions}

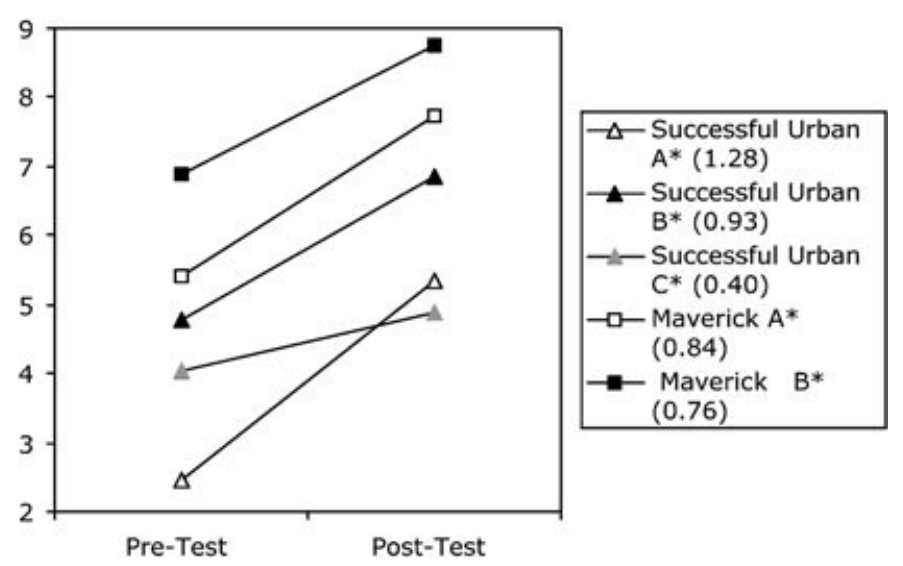

Figure 3. Student pre- and posttest scores (14 points possible) on open-ended items (*: $p<.01)$. Note: Effect sizes are in parentheses.

items, urban students' open-ended pretest scores were lower than maverick students' openended pretest scores. In particular, one urban group, Urban A, demonstrated very low pretest scores, averaging only 2.5 out of a possible 14 points for these items.

By the open-ended posttests, all focus students showed significant gains and high effect size differences between pre- and posttests. These results suggest that focus students, in both urban and maverick teacher classrooms, demonstrated greater and more developed understandings of complex science and inquiry-focused thinking related to weather concepts, even in learning environments that had less experience with inquiry approaches, had many nonnative English speakers and witnessed unreliable Internet technology.

The results on the open-ended items are important for the learning they represent. For the more targeted purposes of this study, these achievement gains are especially important because they provide a case of a challenging, technology-rich science inquiry curriculum experiencing success in diverse classroom environments. The learning results point to an example of an inquiry science curriculum that had strong learning results in a set of very different classroom settings, including differences evident in the classes taught by the focus urban teachers, each of which worked under their own set of conditions that make inquiryorientated pedagogy challenging. Even in classrooms where many students do not speak English fluently, as in Urban A with only $38 \%$ native English speakers, students achieved very large gains and achieved learning outcome levels with inquiry items that begin to "close the gap" seen on pretests between them and their counterparts headed by maverick teachers. The bilingual Urban A teacher commented on her students and how she was able to use KGS effectively,

Urban 10: Half of them have only been here [in the United States] a year or less. But they have advanced very quickly ... as far as the KGS program ... the students enjoyed it very much. Much better than what we were doing before... They know when they come in here they are going to learn something, something is going to be exciting, something is going to be different... Part of my philosophy also comes from Escalante and his statement is "students will rise to the level of expectation" and I believe that wholeheartedly. They will.

The results of this study originate in an initial examination of a large number of classrooms participating in KGS to characterize two kinds of teachers: urban and maverick. From this 
larger sample, a set of five focussed classrooms were selected to more closely investigate the nature of the population, learning environment features, and student realized outcomes in association with the same 8-week inquiry weather program. Examination of the five focus groups revealed that focus maverick teachers had higher levels of access to computer technology, higher levels of autonomy and worked with student populations that were largely White, suburban, and speakers of English as a first language. On balance, focus urban teachers worked largely with students who were non-White, many of whom did not speak English as their first language and did not have access to computers or the Internet outside of this project. When students were evaluated on content and inquiry understandings, maverick students demonstrated higher levels of background knowledge on both traditional and inquiry content, but both maverick and urban students demonstrated significant learning gains on content and inquiry by the posttest. These results suggest that inquiry science programs such as KGS can support a range of students as they both learn about traditional weather content, and demonstrate more complex reasoning associated with weather-related phenomena. In short, this study describes an example of an inquiry curriculum innovation that is successful in diverse settings. As such, the results stand to add to the discussion about an expanded understanding of inquiry science, one that goes beyond one idealized standard.

\section{DISCUSSION}

This research provides information on a range of teachers and learning environments that successfully utilized the KGS Weather inquiry and technology program towards strong learning outcomes by students. This work is prompted by a policy and research context shaped by calls for "scientific literacy for all." There are numerous examples in the literature of successfully implemented science inquiry programs, but many of these are from classrooms led by well-supported teachers who have taken the lead in seeking out innovative science programs. These examples help shape an image of what science inquiry looks like in school settings. While recent documents such as the Inquiry and the National Science Education Standards guide (National Research Council, 2000) claim that inquiry in classrooms often takes a wide variety of forms, few models or clear examples exist that might help expand and characterize this vision of science inquiry to encompass the broad range of diverse schools in which science education takes place. In particular, there are unanswered questions about how the same science inquiry program can be supported in a range of diverse classroom settings, including urban settings where students are often at higher risk for school failure. This work begins a discussion about what successful classroom-based inquiry science looks like in diverse school settings. In doing so, this research also points to the need for further conversation about the images of successful science teaching that drive reform initiatives. In this section, we discuss two contributions this research makes towards a more comprehensive understanding of classroom-based science inquiry. These include calls for expanded models of classroom-based inquiry science, and greater understanding of the concept of scaling of innovations to many diverse settings.

\section{We Need Expanded Views and Models of Classroom-Based Inquiry Science}

Science educators and researchers often hold a narrow, somewhat idealistic representation of scientific inquiry as "the kind of thinking scientists engage in" or other poorly defined constructs, in part, because few other models, and few well-defined models, of inquiry science exist. Consistent with this representation, inquiry guides can often present a 
monolithic view of what inquiry should look like in classrooms. For example, many models of classroom inquiry present small groups of students engaged in a variety of more or less self-guided activities, with the teacher moving from group to group acting as a facilitator or guide. Although this pedagogical approach holds considerable appeal, it is a form of teaching that is quite difficult to achieve in many classrooms. Many teachers, especially those in urban settings, face special challenges and constraints to teaching towards this ideal standard. This study presents evidence of successful science teaching in such environments that do not fit neatly with this standard view of science inquiry. The urban teachers in this study used KGS to bring about powerful science learning, but their classrooms and pedagogical style often differed from that of their maverick peers. How can we use the contrasts and similarities between urban and maverick teachers' experiences to expand our models and understandings of what classroom-based inquiry science could look like? How can we use such variance on the same common theme, the KGS inquiry program, to begin to articulate characteristics of inquiry science beyond one idealized standard?

A full account of an expanded view of classroom-based inquiry science is well beyond the scope of this work, but the comparisons between maverick and urban teachers featured in this study suggest a few starting points. This study provided evidence that both maverick and urban students can demonstrate significant levels of scientific inquiry after utilizing the same KGS Weather inquiry program. Although the program and outcomes were similar, our study also suggests that the nature of classroom practices that led to these outcomes in the various classrooms were somewhat different. Here we offer two distinguishing features in a discussion that addresses classroom use of small and large groups, and issues of partial and full inquiry.

Contrary to the ideal, urban teachers in this study did not embrace small, self-paced groups as a preferred method of teaching. Teacher survey and interview data indicate that almost half of the maverick teachers favor students working in small, self-paced groups while only $18 \%$ of urban teachers favor this approach. Our observations and teacher interviews revealed that most urban teachers performed many of the inquiry activities with the whole class doing the same activity at one time. In contrast, maverick teachers described splitting their class into small groups and assigning different tasks for each group, a pedagogical model often associated with inquiry learning. Maverick teachers, with their smaller class size, could implement small groups more easily than urban teachers. In addition, the support structures and level of autonomy tended to be stronger for maverick than urban teachers. These differences may support a greater tendency among maverick teachers to turn more control and ownership of learning within small groups over to students. With an average class size of 31 , little autonomy, and no classroom aides, urban teachers simply might need to implement whole-class activities to achieve any modeling or guidance at all of inquiry learning.

In an interview, one urban teacher comments on how he makes large-group inquiry work

Urban 12: And most of the time I'm very successful doing whole class instruction because I've got their attention for the most part. And I get their attention because they know that I care about them.

In this teacher's classroom, as well as those of many of his urban peers, science inquiry gains were realized through classroom practices that depart from the commonly held vision of what successful inquiry science teaching looks like. Therefore contrary to what might be an ideal of scientific inquiry practice, this research suggests that some pedagogical approaches often described as essential for fostering inquiry, such as small autonomous groups, can be adapted towards classroom practices that are better suited to particular audiences, such as 
students with little prior inquiry experience or students in classrooms of very large class sizes. Research that characterizes and provides more varied models of classroom-based inquiry can help a wider range of practitioners and learners to find mechanisms to adapt inquiry science practices to their needs more easily.

Recently, inquiry guides such as Inquiry and the National Science Education Standards (National Research Council, 2000) have begun to discuss variations that might help science educators realize a more expanded understanding of classroom inquiry. Within this guide, the authors present suggestions of how a particular inquiry feature can be implemented in classrooms in various ways, depending on the amount of ownership and structure imposed by the teacher as contrasted to the amount of ownership assumed by students. For example, when discussing variations on the inquiry feature, learner engages in scientifically oriented questions, the inquiry guide presents four variations of this same inquiry feature, from a more teacher-directed version (learner engages in questions provided by teacher, materials, or other source) to a more student-directed version (learner poses a question) (National Research Council, 2000, p. 29). While each of these variations are regarded as inquiry thinking by students, the guide recommends that students less familiar with inquiry activities might begin with the more teacher-directed version, and over time and experience, move towards the more student-directed version. While there is still a great deal of work necessary to transform the NRC recommendations into activities that promote in-depth, inquiry activities among a range of students, the guide presents a compelling first-step dialogue towards the kinds of expanded understandings of inquiry science that we advocate. Extending this dialogue in a hypothetical way to our urban and maverick teachers' classroom examples, we would speculate that our teachers who are working with students less familiar with inquiry thinking and with a large class size might choose to enact this inquiry feature using a whole-class discussion to model the process of selecting good questions for further investigation, or they might model the process of shifting a fact-based "what" or "how many" question into a "how" or "why" investigative question using criteria for good driving questions (Krajcik et al., 1994). In this example we wish to illustrate that pedagogical variations on inquiry thinking need to be more fully articulated that might promote questioning, explanation-building, and critical thinking that maintains the integrity of the inquiry activities, while they provide support and guidance appropriate for the audience, experience-level, and class size present.

While the NRC guide is not explicit on when or how the different versions might be implemented, research here suggests that one promising approach might be the organization of a large set of coordinated, inquiry-fostering activities that support increasing levels of autonomy throughout a comprehensive curricular sequence. This coordinated sequence could be implemented with cohorts of students who are then assessed in their ability to develop inquiry and content thinking longitudinally, through multiple, coordinated inquiry units over a multiyear program. Currently, our research group is conducting research of this kind to examine longitudinal inquiry and content thinking in urban middle school students from fifth through eighth grade. We encourage other research studies that help illustrate multiple models of classroom-based inquiry, and longitudinal development of inquiry thinking.

Another feature of inquiry science that needs greater expansion is the dimension of "partial" or "full" inquiry. The National Research Council (2000, Inquiry and the National Science Education Standards) distinguishes between "partial" and "full" inquiries. Partial inquiries refer to situations where teachers provide components of the inquiry learning experience, such as demonstrating how to do an experiment rather than allowing students to conduct the complete experiment on their own. Full inquiries are those that put students in charge of the design, implementation, and evaluation of classroom-based inquiry. Most 
curricular programs select one level of inquiry for each activity, i.e. partial or full, and provide guidance for teachers on how to implement only that presentation level. Prevailing standards of inquiry science hold forth a preference for full inquiries as the ideal. This study of maverick and urban teachers suggests that if our task is to develop inquiry resources that can easily be adapted to a wide range of learners, we need research leading to curricular programs that support both partial and full approaches to the content. The need is for flexible models that provide guidance for students and teachers who are comfortable with more autonomy and open-endedness, as well as for students and teachers who have little previous inquiry experience and need more guidance. The latter may benefit from partial, more structured versions of the same activities.

In this study, urban teachers successfully adapted KGS to pedagogical approaches that do not perfectly match with the idealized view of inquiry science in classrooms. In doing so, these teachers provide an important reminder to science educators-science inquiry is more about substance than it is about form. In thinking about what science inquiry looks like in diverse school settings, the quality of the intellectual engagement among students should hold more sway that making sure classroom methods match with a pre-established vision of best practice. In short, best practice in one setting may not look like best practice in another. Certainly, the set of challenges faced by teachers in many urban school settings calls for flexibility and creativity in developing pedagogy to meet the substantive goal of science inquiry. Curricular programs that provide veteran teachers online or a set of short video cases that include both partial and full inquiry exemplars packaged with the curricular resources themselves might begin to help a range of learners to find a good level of support and guidance that facilitates both their own inquiry and rich inquiry learning among their students. Without more guidance and cases that exemplify the manner in which adaptations are expected and suggested, understanding and supporting "inquiry for all" remains an unattainable goal.

\section{Inquiry Programs Should Support Large Scale Not Scaling}

Scaling is a major thrust of educational reform initiatives. Obviously without broad impact in a large number of schools, reforms run the risk of making no lasting change on the educational landscape. One of the clear lessons of this work is that curricular programs cannot be scaled in the sense of providing cookie-cutter curriculum for implementation in one particular way in a wide variety of school settings. Scaling research should be driven less by a concern for making sure that a particular curriculum is carried out in lots of classrooms according to a preset script. Rather, the focus should be on large-scale success in helping students realize gains in their understanding of inquiry science. Here the difference is one of emphasis. At the same time that we support the implementation of our program in many schools simultaneously, there is no expectation that KGS be implemented in the same manner in any two schools. We build learning environments that we fully expect teachers will adapt to their local classroom, level of technology, and student population. As this study suggests, the resources and constraints that individual teachers encounter are diverse across sites, and they cannot all lead to the same enactment even if they lead, as in this case, to similar promising outcomes. The success of KGS in urban school environments suggests that scaling attempts are misguided if they seek to realize a "one size fits all" approach to pedagogy, without regard to the set of features comprising different learning contexts.

Therefore our research suggests a rethinking of research-driven scaling to honor the complexity of the constraints and affordances experienced by teachers in diverse school settings. In the case of the urban teachers featured in this research, KGS needed to make room for methods of teaching that included large-group and sometimes teacher-centered 
forms of inquiry pedagogy. In doing so, KGS appeared to support the development of deep conceptual and inquiry understandings among a diverse group of students, in varied classroom contexts. Research should continue to explore what it means to support a diverse range of high-quality implementations on a large scale, rather than ways to customize the learning environment and population to meet one set of inquiry standards and approaches. Science educators need to look broadly, and with flexibility, as they expand their view of what inquiry science looks like in diverse school settings. Although this is a small step in that direction, the hope is that further research will continue productive conversation about models of classroom inquiry across the full range of diverse classrooms, including those of nonmaverick teachers, and those within low SES urban settings. This conversation must advance if "science literacy for all" is to be embraced within the wide spectrum of our science classrooms.

Thanks to Michelle Astolfi, Todd Dinkelman, Monica Hartman, Joe Krajcik, and Richard Duschl for their assistance with this paper.

\section{REFERENCES}

Ball, D. L., \& Cohen, D. K. (1996). Reform by the book: What is-or might be-the role of curriculum materials in teacher learning and instructional reform? Educational Researcher, 25(9), 6-14.

Blumenfeld, P. C., Fishman, B. J., Krajcik, J. S., Marx, R. W., \& Soloway, E. (2000). Creating useable innovations in systemic reform: Scaling up technology-embedded project-based science in urban schools. Educational Psychologist, 35(3), 149-164.

Bransford, J. D., Brown, A. L., \& Cocking, R. (2000). How people learn: Brain, mind experience and school. Washington, DC: National Academy Press.

Chi, M. T. H. (1997). Quantifying qualitative analyses of verbal data: A practical guide. The Journal of the Learning Sciences, 6(3), 271-315.

Emmer, E. (1986). Academic activities and tasks in first-year teachers' classes. Report No. 6025. Austin, TX: University of Texas, Research and Development Center for Teacher Education.

Haberman, M. (1991). The pedagogy of poverty versus good teaching. Phi Delta Kappan, 73, 290294.

Hurd, P. D. (1997). Inventing science education for the new millennium. New York: Teachers College Press.

Kahle, J., Meece, J., \& Scantlebury, K. (2000). Urban African-American middle school science students: Does standards-based teaching make a difference? Journal of Research in Science Teaching, 27(9), 1019-1041.

Krajcik, J. S., Blumenfeld, P. C., Marx, R. W., \& Soloway, E. (1994). A collaborative model for helping middle grade science teacher learn project-based instruction. The Elementary School Journal, 94 , 483-497.

Lee, H. S., \& Songer, N. B. (in press). Making authentic science accessible to students. International Journal of Science Education.

Lehrer, R., Carpenter, S., Schauble, L., \& Putz, A. (2000). Designing classrooms that support inquiry. In J. Minstrell \& É. van Zee (Eds.), Inquiring into inquiry learning and teaching in science (pp. 313). Washington, DC: AAAS.

Metz, K. (2000). Young children's inquiry in biology: Building the knowledge bases to empower independent inquiry. In J. Minstrell \& É. van Zee (Eds.), Inquiring into inquiry learning and teaching in science (pp. 3-13). Washington, DC: AAAS.

Merriam, S. B. (1998). Qualitative research and case study applications in education. San Francisco: Jossey-Bass.

National Research Council (1996). National science education standards. Washington, DC: National Academy Press. 
National Research Council (2000). Inquiry and the national science education standards. Washington, DC: National Academy Press.

Owens, E. H. (1992). The NAEP 1990 Science Report Card. Washington, DC: National Center for Education Statistics.

PCAST (1997). Report to the President on the use of technology to strengthen K-12 education in the United States. March. www.pcast.

Slavin, R., Dolan, L., \& Madden, N. (1996). Scaling up: Lessons learned in the dissemination of success for all. Available at http://hunix.hcf.jhu.edu/ reneek/scaling.html.

Songer, N. B., Lee, H.-S., \& Kam, R. (2002). Technology-rich inquiry science in urban classrooms: What are the barriers to inquiry pedagogy? Journal of Research in Science Teaching, 39(2), 128 150 .

Songer, N. B., \& McDonald, S. (2001, Winter). Smiling while guiding thirty sixth graders through Internet-based curricula when the Internet is down. ERIC Update, 22(2).

Songer, N. B. (1998). Can technology bring students closer to science? In K. Tobin \& B. Fraser (Eds.), The international handbook of science education (pp. 333-348). The Netherlands: Kluwer.

Songer, N. B., Devaul, H., Hester, P., Crouch, S., Kam, R., Lee, H. S., \& Lee, S. Y. (2000). Kids as global scientists: Weather!: An eight-week inquiry curriculum for middle school atmospheric science. The University of Michigan.

Songer, N. B., \& Samson, P. (2000). Internet-enabled multimedia that supports inquiry understandings in middle school digital learning environments. Paper presented at the annual meeting of the American Educational Research Association, New Orleans, LA, April.

Teel, K. M., Debruin-Parecki, A., \& Covington, M. (1998). Teaching strategies that honor and motivate inner-city African-American students: A school/university collaboration. Teaching and Teacher Education, 14(5), 479-495.

U.S. House of Representatives (2001). Committee on science hearing charter: Classroom as laboratories: The science of learning meets the practice of teaching. Available at http://www.house.gov/science/research/may10/res_charter_051001.htm.

White, B. Y., \& Frederiksen, J. R. (1998). Inquiry, modeling, and metacognition: Making science accessible to all students. Cognition and Instruction, 16(1), 3-118.

Yorker, C., \& Songer, N. B. (1999). The challenges and affordances of enacting a reform-minded middle school science and technology program: Teachers' voices on creating new roles. Paper presented at the Annual Meeting of the American Educational Research Association, Montreal, Canada. 